\title{
PENGENALAN PEMANDUAN LALU LINTAS PENERBANGAN (AIR TRAFFIC CONTROL) DI INDONESIA
}

\author{
Djoko Jatmoko ${ }^{1)}$; Lina Rosmayanti ${ }^{2)}$; Nunuk Praptiningsih ${ }^{3)}$; Rany Adiliawijaya Putriekapuja ${ }^{4}$; Elfi \\ Amir $^{5)}$; Ikhsan Wahyu Vebriyan'); Nadiya Rizki Azizah ${ }^{7)}$ \\ 1) djoko.jatmoko@ppicurug.ac.id, Politeknik Penerbangan Indonesia Curug, Tangerang, Banten \\ 2) lina.rosmayanti@ppicurug.ac.id ${ }^{*}$, Politeknik Penerbangan Indonesia Curug, Tangerang, Banten \\ 3) nunuk.praptiningsih@ppicurug.ac.id, Politeknik Penerbangan Indonesia Curug, Tangerang, Banten \\ 4) rany.adiliawijaya@ppicurug.ac.id, Politeknik Penerbangan Indonesia Curug, Tangerang, Banten \\ 5) tevimc@gmail.com, Politeknik Penerbangan Indonesia Curug, Tangerang, Banten \\ 6) ikhsan.wahyu@gmail.com, Politeknik Penerbangan Indonesia Curug, Tangerang, Banten \\ 7)nadiyarizky@ppicurug.ac.id, Politeknik Penerbangan Indonesia Curug, Tangerang, Banten \\ * untuk penulis korespondensi
}

\begin{abstract}
Not a few graduates from the Dirghantara Aviation Vocational School and Yappika Legok Vocational School who choose to continue their education at PPI Curug, but only a few graduates choose to major in Air Traffic Control. Due to the lack of interest in the graduates of the Dirghantara Aviation Vocational School and the Yappika Legok Vocational School, it is deemed necessary to have activities that can build interest in the Air Traffic Control major, namely through Community Service activities. The method used is face-to-face socialization at the PPI Curug Aviation Safety Building which is carried out in accordance with health protocols. The results of the service obtained are that it is hoped that students from the Vocational School know more about air traffic control and can spread knowledge to their friends so that students who have interest and curiosity able to understand more deeply the purpose of air traffic control. routinely either in the same location or in different locations with different target communities by other study programs. Socialization of professions in the field of aviation and study programs at PPI Curug to the public can be carried out with a wider scope nationally by collaborating with the Education Office online/video conference.
\end{abstract}

Keywords : Air Traffic Control, Vocational School, Graduates

Abstrak

Tidak sedikit lulusan dari SMK Penerbangan Dirghantara dan SMK Yappika Legok yang memilih untuk melanjutkan pendidikannya di PPI Curug, namun hanya sedikit yang memilih jurusan Pemanduan Lalu Lintas Udara. Dikarenakan kurangnya minat lulusan SMK Penerbangan Dirghantara dan SMK Yappika Legok tersebut, maka dirasa perlu adanya kegiatan yang dapat menumbuhkan minat terhadap jurusan Pemanduan Lalu Lintas Udara yaitu melalui kegiatan Pengabdian kepada Masyarakat. Metode yang digunakan adalah sosialisasi secara tatap muka di Gedung Keselamatan Penerbangan PPI Curug yang dilaksanakan sesuai dengan protokol kesehatan. Hasil pengabdian yang didapatkan adalah diharapkan pelajar dari SMK tersebut dapat lebih mengenal mengenai pemanduan lalu lintas udara dan dapat menyebarkan ilmu terhadap temannya sehingga muncullah pelajar yang memiliki minat dan keingintahuan untuk dapat memahami lebih dalam maksud dari pemanduan lalu lintas udara.kegiatan pengabdian seperti ini dapat dilakukan secara rutin baik di lokasi yang sama maupun di lokasi berbeda dengan sasaran masyarakat yang berbeda oleh program studi lainnya. Sosialisasi mengenai profesi di bidang penerbangan dan program studi di PPI Curug kepada masyarakat dapat dilakukan dengan cakupan yang lebih luas lagi secara nasional dengan bekerja sama dengan Dinas Pendidikan secara daring/video conference.

Kata Kunci : Air Traffic Control, SMK, Lulusan

\section{PENDAHULUAN}

Pandemi Covid-19 yang terjadi diawal tahun 2020 merubah banyak hal baik dibidang ekonomi, transportasi, sosial, budaya khususnya didunia pendidikan (Arnas, Y; Lamtiar, S; Kurniawati, Z; Kurnianto, B; Kalbuana, 2021; Dewi, Yani, Yohana, Kalbuana, \& Tho’in, 2021; Hastomo, Karno, Kalbuana, Nisfiani, \& ETP, 2021; Hendriarto, Mursidi, Kalbuana, Aini, \& Aslan, 2021; Kalbuana, N; Christelia, S; Kurnianto, B; Purwanti, T; Tho'in, 2021; Kalbuana, Sutadipraja, Purwanti, \& Santoso, 2019; Nurwati, Prastio, \& Kalbuana, 2021; Prasetyo, B; Utami, S; Abdusshomad, A; Wijaya, M; Kalbuana, 2021; Yohana; Kalbuana, N; Solihin; Yanti, 2020; Yohana, Gaol, Dewi, Kalbuana, \& Abdusshomad, 2021). Salah satu kegiatan tri dharma perguruan tinggi berupa kegiatan pengabdian masyrakat tetap wajib dilakukan oleh perguruan 
tinggi (Arti, Praptiningsih, P, \& Sadiatmi, 2020; Haris, Rosmayanti, Darjono, Purwaningtyas, \& Sugih, 2021). Pengabdian kepada masyarakat merupakan media untuk menghubungkan masyarakat sekitar dengan dunia pendidikan (Arnas et al., 2021; Kalbuana et al., 2021; Prasetyo, Rohman, Solihin, Sundoro, \& Kalbuana, 2021; Sihono, Fatkhulloh, Saputro, Herwanto, \& Kalbuana, 2021; Sihono, Fatkulloh, et al., 2021; Toni, Wildan, Purnomo, Wahyudi, \& Fatra, 2022).

Pada kegiatan pengabdian kepada masyarakat pada program studi D.IV Lalu Lintas Udara (D.IV LLU) Politeknik Penerbangan Indonesia Curug (PPI Curug) dilaksanakan dan bermitra dengan SMK Yappika Legok dan SMK Penerbangan Dirghantara yang letak kedua sekolah ini tidak jauh dari kampus PPI Curug. Lulusan dari kedua sekolah ini banyak yang memilih jurusan penerbang atau teknik penerbangan di PPI Curug. Dikarenakan kurangnya minat lulusan dari SMK tersebut untuk melanjutkan pendidikannya di Program Studi Lalu Lintas Udara yang menjadi keilmuan utama di PPI Curug, maka dirasa perlu adanya kegiatan yang dapat menumbuhkan minat dan bakat para pelajar terhadap ilmu penerbangan khususnya dibidang Pemanduan Lalu Lintas Penerbangan (Air Traffic Control). Kurangnya minat calon lulusan tersebut diduga akibat minimnya pengetahuan calon lulusan tersebut terhadap Pemanduan Lalu Lintas Udara.

Kegiatan ini merupakan suatu media untuk menghubungkan dunia pendidikan dengan masyarakat yang salah satunya yaitu pelajar SMK Penerbangan Dirghantara dan SMK Yappika Legok. Kegiatan ini menjelaskan apa yang dimaksud sebagai pemandu lalu lintas udara, apa saja yang dilakukan, mengontrol pesawat dalam area yang mana, segala hal yang berhubungan dengan lalu lintas udara. Diharapkan setelah mengikuti kegiatan sosialisasi ini beberapa pelajar tersebut dapat lebih mengenal pemanduan lalu lintas udara dan dapat menyebarkan ilmu tersebut terhadap temannya sehingga muncullah pelajar yang memiliki minat dan keingintahuan untuk dapat memahami lebih dalam maksud dari pemanduan lalu lintas udara melalui Program Studi D.IV Lalu Lintas Udara yang ada di PPI Curug.

\section{METODE}

Tahapan kegiatan pengabdian kepada masyarakat ini secara garis besar terdiri dari:

\section{Tahap Persiapan}

Pada tahap ini beberapa aktivitas pengabdian kepada masyarakat yang dilakukan dengan melakukan koordinasi dengan mitra pengabdian kepada masyarakat yaitu SMK Penerbangan Dirghantara dan SMK Yappika Legok, permohonan ijin kegiatan pengabdian kepada masyarakat kepada Kepala Sekolah SMK Penerbangan Dirghantara dan SMK Yappika Legok, pengurusan administrasi (surat-menyurat), persiapan alat dan bahan serta akomodasi, persiapan tempat untuk kegiatan pengenalan pemanduan lalu lintas penerbangan yaitu lobby Gedung Jurusan Keselamatan Penerbangan PPI Curug.

\section{Tahap Pelaksanaan}

Sasaran pada kegiatan PKM ini adalah pelajar dari SMK Penerbangan Dirghantara dan SMK Yappika Legok. Kegiatan PKM ini dilaksanakan di Lobby Gedung Keselamatan Penerbangan PPI Curug pada hari Rabu, 24 November 2021. Dimulai pukul 07.30, dilakukan secara tatap muka dan tetap menjalankan protokol kesehatan. Peserta PKM diberikan seminar kit yang berisi dua handout materi kegiatan yaitu Aerodrome Control Tower dan Approach \& Area Control Procedural serta Personel Pemandu Lalu Lintas Penerbangan (Air Traffic Controller), pulpen, masker, serta handsanitizer. 


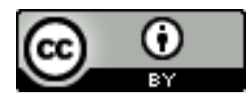

\section{Tahap Pelaporan}

Pada tahap ini, diharapkan pelajar dari SMK Penerbangan Dirghantara dan SMK Yappika Legok dapat lebih mengenal tentang mengenai pemanduan lalu lintas udara dan dapat menyebarkan ilmu tersebut terhadap temannya sehingga pelajar lain memiliki minat dan keingintahuan yang untuk dapat memahami lebih dalam maksud dari pemanduan lalu lintas udara melalui program studi D.IV Lalu Lintas Udara yang ada di Politeknik Penerbangan Indonesia Curug. Bagi para Dosen/Instruktur yang ikut serta sebagai Pelaksana dharma perguruan tinggi, pelaporan dihasilkan dalam bentuk naskah laporan serta jurnal yang dipublikasi.

\section{HASIL DAN PEMBAHASAN}

Kegiatan pengabdian kepada masyarakat Prodi D.IV Lalu Lintas Udara dilaksanakan di lobby Gedung Keselamatan PPI Curug. Kegiatan tersebut dilaksanakan pada hari Rabu, 24 November 2021. Kegiatan ini dimulai pukul 07.30 WIB, dimana peserta kegiatan pengabdian kepada masyarakat yaitu peserta dari SMK Penerbangan Dirghantara dan SMK Yappika Legok telah datang dan langsung melakukan registrasi di bagian depan Gedung Keselamatan Penerbangan. Kegiatan ini tetap melaksanakan protokol kesehatan disertai pemberian seminar kit yang berisi handout materi kegiatan PKM, pulpen, masker serta handsanitizer.

Gambar 1

Registrasi peserta dan pemberian seminar kit
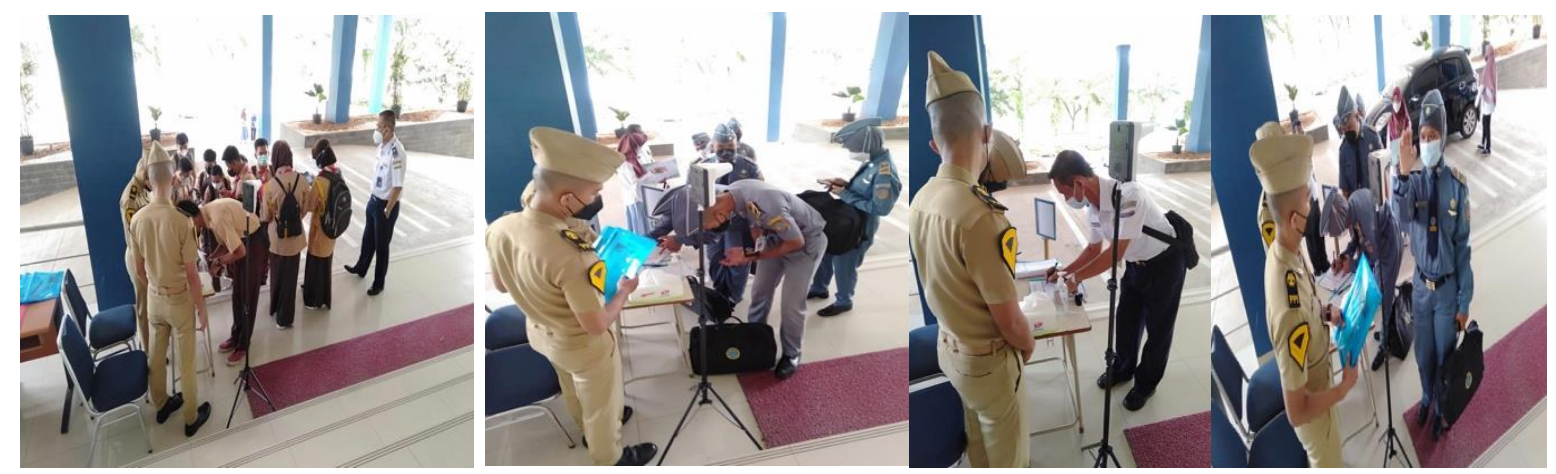

Selanjutnya acara dimulai dengan laporan dari Koordinator media dan administrasi yaitu Ibu Lina Rosmayanti dilanjutkan sambutan dari guru pendamping SMK Kejuruan Yappika Legok yaitu Noviadi Eko dan perwakilan guru pendamping dari SMK Penerbangan Dirghantara yaitu Ibu Eva Sulastri. Sambutan kegiatan diakhiri oleh Kepala Bagian Admininistrasi Akademik dan Ketarunaan yaitu Bapak Sukarwoto. 


\section{PENGMASKU}

Volume 2 No. 1, 2022

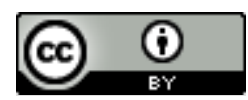

Gambar 2

Pembukaan Acara PKM Prodi D.IV LLU
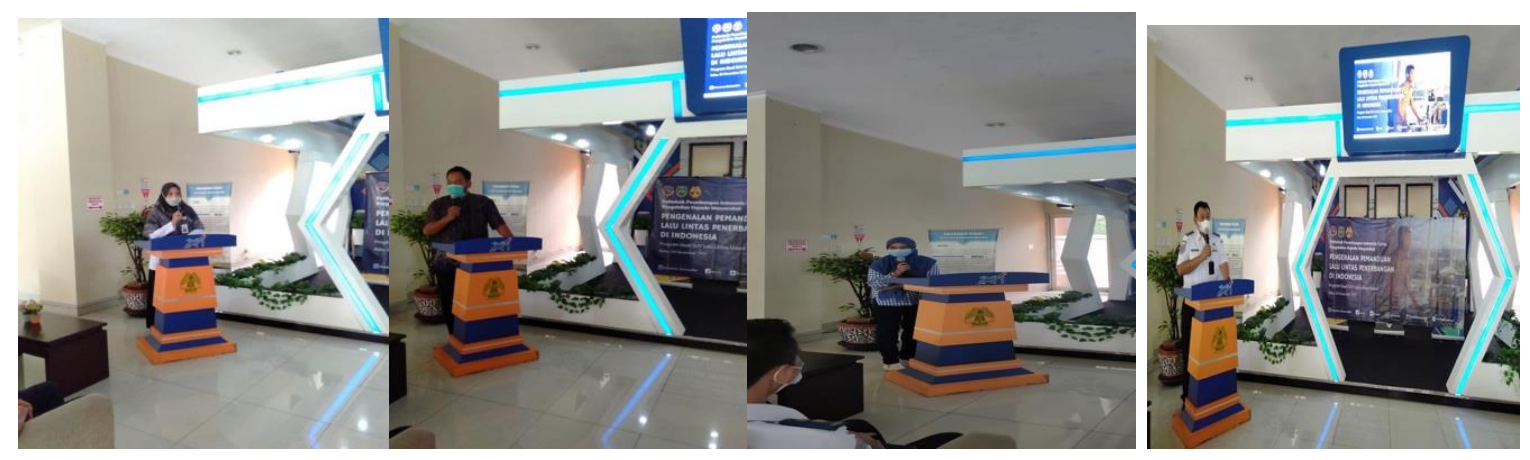

Penyampaian materi pertama disampaikan oleh Bapak Djoko Jatmoko yang memberikan 2 materi yaitu Aerodrome Control Tower dan Approach \& Area Control Procedural dan Radar, yang mana setiap materi disampaikan selama 30 menit. Kemudian pada pukul 10.10 WIB, dilanjutkan oleh narasumber kedua yaitu Bapak Elfi Amir memberikan materi dengan judul Personel Pemandu Lalu Lintas Penerbangan (Air Traffic Controller). Setelah seluruh materi tersampaikan, dilanjutkan sesi tanya jawab yang berlangsung kurang lebih 15 menit dimana peserta diberikan kesempatan untuk mengajukan pertanyaan seputar materi yang diberikan kepada narasumber.

Gambar 3

\section{Pemberian Materi PKM Prodi D.IV LLU}

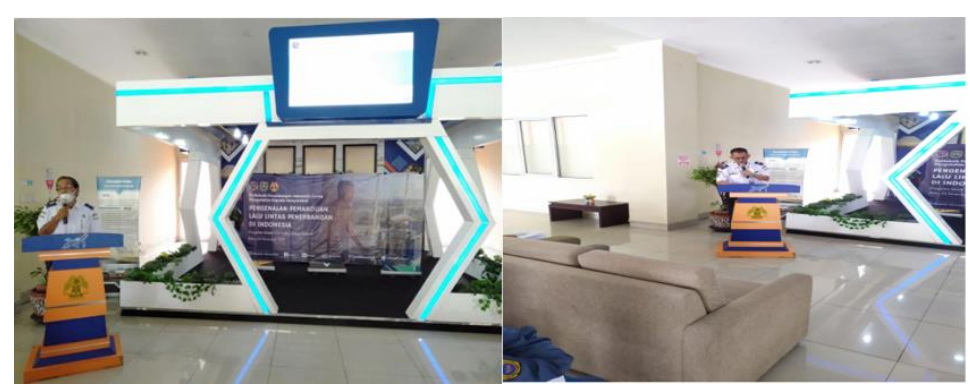

Setelah sesi tanya jawab berakhir, kegiatan dilanjutkan dengan melakukan visitasi ke laboratorium yang ada di Gedung Keselamatan Penerbangan PPI Curug dan melihat demo di Lab. Aerodrome Control Tower, Lab. Approach Control Procedural dan Lab. Approach Control Surveillance (Radar). 


\section{PENGMASKU}

Volume 2 No. 1, 2022

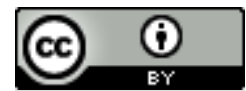

Gambar 4

Visitasi ke Lab Simulator ATC di Gedung Keselamatan Penerbangan PPI Curug

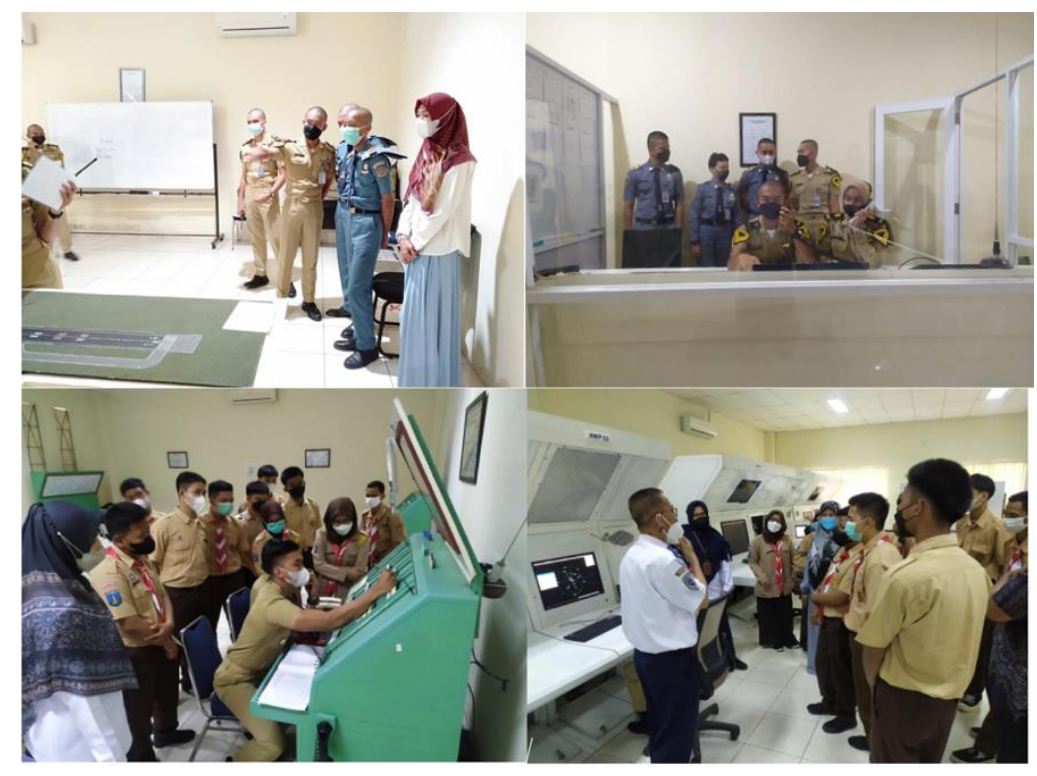

Setelah visitasi dilaksanakan, kegiatan selanjutnya adalah pemberian sertifikat kepada guru pendamping dari SMK Penerbangan Dirghantara dan SMK Kejuruan Yappika Legok serta kepada perwakilan siswa tiap sekolah.

\section{Gambar 5}

\section{Pemberian Sertifikat kepada Peserta PKM}

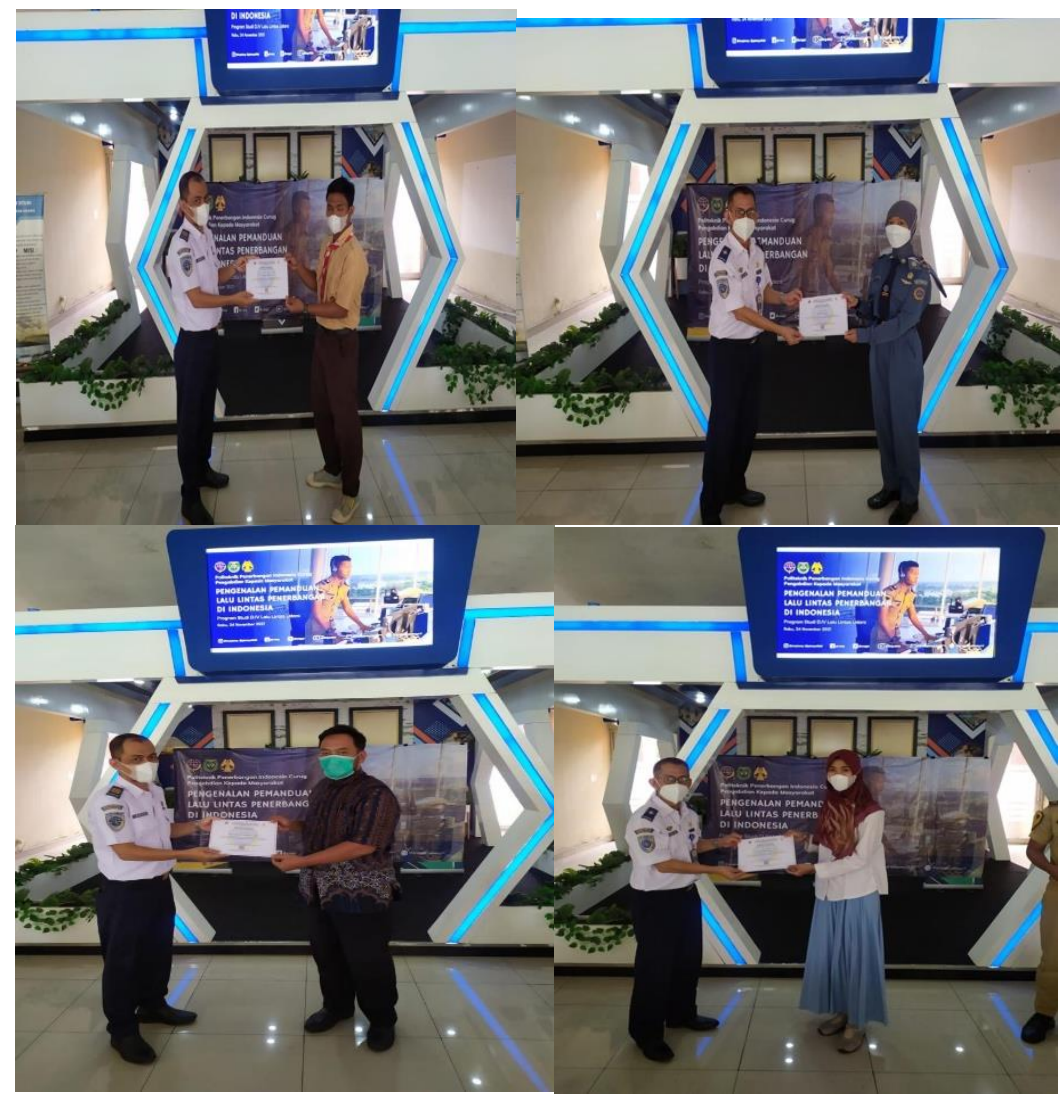




\section{PENUTUP}

\section{Simpulan}

Kegiatan PKM tentang Pengenalan Pemanduan Lalu Lintas Penerbangan (Air Traffic Control) di Indonesia ini bermitra dengan SMK Yappika Legok dan SMK Penerbangan Dirghantara yang dilaksanakan pada hari Rabu tanggal 24 Nopember 2021 di lobby Gedung Keselamatan Penerbangan PPI Curug. Peserta tampak antusias mendengarkan materi yang telah dipaparkan oleh narasumber dan juga dilakukan visitasi ke laboratorim yang ada di Gedung Keselamatan PPI Curug. Diharapkan setelah kegiatan sosialisasi ini dilaksanakan dapat menumbuhkan minat dan keingintahuan pelajar untuk melanjutkan studi di Program Studi pemanduan lalu lintas udara melalui Program Studi D.IV Lalu Lintas Udara PPI Curug

\section{Penghargaan}

Penghargaan yang tinggi kami berikan kepada Kementerian Perhubungan RI, Badan Pengembangan SDM Perhubungan, Pusat Pengembangan SDM Perhubungan Udara dan khususnya kepada Direktur Politeknik Penerbangan Indonesia Curug melalui Pusat Penelitian dan Pengabdian kepada Masyarakat atas dana hibah PKM yang diperoleh sehingga dapat menyelenggarakan kegiatan ini serta kepada siswa dan guru pendamping dari SMK Penerbangan Dirghantara dan SMK Yappika Legok.

\section{DAFTAR PUSTAKA}

Arnas, Y; Lamtiar, S; Kurniawati, Z; Kurnianto, B; Kalbuana, N. (2021). Factors Affecting Earning Management On Transportation Corporations In Indonesia. International Journal of Economics, Business and Accounting Research (IJEBAR), 5(1), 150-159. Diambil dari https://jurnal.stie-aas.ac.id/index.php/IJEBAR/article/view/2170/1012

Arnas, Y., Ismail, K. G. S. M., Kurniawati, Z., Kurnianto, B., Wibowo, I. H., \& Kalbuana, N. (2021). Pelatihan perawatan / service AC untuk masyarakat sekitar Politeknik Penerbangan Indonesia Curug. Penamas: Journal of Community Service, 1(2), 90-99.

Arti, E. S., Praptiningsih, N., P, R. A., \& Sadiatmi, R. (2020). Pengenalan Pelayanan Lalu Lintas Udara ( Air Trafic Service ) di Indonesia. Jurnal Pengabdian Kepada Masyarakat (JPKM) Langit Biru, 1(1), 1-6.

Dewi, G. K., Yani, I. F., Yohana, Kalbuana, N., \& Tho'in, M. (2021). Pengaruh GCG, Leverage, Pengungkapan CSR terhadap Performance Financial pada Perbankan Syariah di Indonesia dengan Ukuran Perusahaan sebagai Variabel Moderasi | Dewi | Jurnal Ilmiah Ekonomi Islam. Jurnal Ilmiah Ekonomi Islam, 7(3). Diambil dari https://jurnal.stie-aas.ac.id/index.php/jei/article/view/3600

Dinas Pendidikan Kabupaten Tangerang, www.tangerangkab.go.id/disdik diakses pada tanggal 16 Juni 2021.

Haris, F. M., Rosmayanti, L., Darjono, W., Purwaningtyas, D. A., \& Sugih, E. (2021). EAST VFR Route Design at Airnav Indonesia Banjarmasin Branch Office. International Journal of Progressive Sciences and Technologies (IJPSAT), 30(1), 557-566.

Hastomo, W., Karno, A. S. B., Kalbuana, N., Nisfiani, E., \& ETP, L. (2021). Optimasi Deep Learning untuk Prediksi Saham di Masa Pandemi Covid-19. JEPIN (Jurnal Edukasi dan Penelitian Informatika), 7(2), 133-140. Diambil dari https://jurnal.untan.ac.id/index.php/jepin/article/view/47411

Hendriarto, P., Mursidi, A., Kalbuana, N., Aini, N., \& Aslan, A. (2021). Understanding the Implications of Research Skills Development Framework for Indonesian Academic Outcomes Improvement. Jurnal Iqra': Kajian Ilmu Pendidikan, 6(2), 51-60. https://doi.org/10.25217/JI.V6I2.1405 
International Civil Aviation Organization. (2016). Annex 11 Air Traffic Services 14th Edition. Montreal: International Civil Aviation Organization

International Civil Aviation Organization. (2016). Doc.4444 Air Traffic Management 16th Edition. Montreal: International Civil Aviation Organization

Kalbuana, N; Christelia, S; Kurnianto, B; Purwanti, T; Tho'in, M. (2021). Pengaruh Ukuran Perusahaan, Leverage dan Nilai Perusahaan Terhadap Tax Avoidance Kasus Perusahaan Yang Terdaftar Di Jakarta Islamic Index (JII). Jurnal Ilmu Manajemen dan Akuntansi Terapan (JIMAT), 12(2), 190-202. Diambil dari http://jurnal.stietotalwin.ac.id/index.php/jimat/article/view/340/258

Kalbuana, N., Hendra, O., Aswia, P. R., Lestary, D., Kardi, \& Solihin. (2021). Pengenalan Unit Penanggulangan Keadaan Darurat Di Bandara Bagi Siswa SMK Penerbangan di Wilayah Lampung dan Sidoarjo. Jubaedah : Jurnal Pengabdian dan Edukasi Sekolah, 1(3), 232-239.

Kalbuana, N., Sutadipraja, M. W., Purwanti, T., \& Santoso, D. (2019). Pengaruh Profitabilitas, Leverage, Kinerja Lingkungan Terhadap Pengungkapan Islamic Social Reporting (Studi Empiris pada Perusahaan yang Terdaftar di JII Tahun 2013-2017). AKTSAR: Jurnal Akuntansi Syariah, 2(2), 233-248. Diambil dari https://journal.iainkudus.ac.id/index.php/aktsar/article/view/6037

Kementerian Pendidikan dan Kebudayaan, www.jdih.kemdikbud.go.id diakses pada tanggal 19 April 2021Prasetyo, B., Rohman, T., Solihin, S., Sundoro, S., \& Kalbuana, N. (2021). Sosialisasi Kawasan Keselamatan Operasi Penerbangan (KKOP). Jurnal Pengabdian Kepada Masyarakat (JPKM) Langit Biru, 2(1), 31-38. https://doi.org/10.54147/JPKM.V2I01.451

Nurwati, N., Prastio, P., \& Kalbuana, N. (2021). Influence of Firms Size, Exchange Rate, Profitability and Tax Burden On Transfer Pricing. International Journal of Economics, Business and Accounting Research (IJEBAR), 5(3). https://doi.org/10.29040/IJEBAR.V5I3.2882

Peraturan Menteri Perhubungan Republik Indonesia PM 65 Tahun 2017 tentang Peraturan Keselamatan Penerbangan Sipil Bagian 170 tentang Peraturan Lalu Lintas Penerbangan

Peraturan Menteri Perhubungan Republik Indonesia Nomor PM 14 Tahun 2019 tentang Peraturan Keselamatan Penerbangan Sipil Bagian 69 tentang Lisensi, Rating, Pelatihan, dan Kecakapan Personel Navigasi Penerbangan

Politeknik Penerbangan Indonesia Curug (2020). Panduan Penelitian dan Pengabdian Kepada Masyarakat. Tangerang.

Prasetyo, B; Utami, S; Abdusshomad, A; Wijaya, M; Kalbuana, N. (2021). Effect Of Company Value, Leverage, And Company Size On Profit Persistence In Jakarta Islamic Index (JII) Listed Companies. International Journal of Economics, Business and Accounting Research (IJEBAR), 5(1), 128-136. Diambil dari https://jurnal.stieaas.ac.id/index.php/IJEBAR/article/view/2164/1010

Prasetyo, B., Rohman, T., Solihin, S., Sundoro, S., \& Kalbuana, N. (2021). Sosialisasi Kawasan Keselamatan Operasi Penerbangan (KKOP). Jurnal Pengabdian Kepada Masyarakat (JPKM) Langit Biru, 2(1), 31-38. https://doi.org/10.54147/JPKM.V2I01.451

Sihono, S., Fatkhulloh, A., Saputro, R., Herwanto, D., \& Kalbuana, N. (2021). Pendalaman Buku Ajar Elektrikal dan Elektronika Pesawat Udara Bagi Guru SMK Penerbangan. Jurnal Pengabdian Kepada Masyarakat (JPKM) Langit Biru, 2(1), 46-54. https://doi.org/10.54147/jpkm.v2i01.462 
Sihono, S., Fatkulloh, A., Saputro, R., Herwanto, D., Kalbuana, N., \& Kurnianto, B. (2021). Pemantapan Dan Refreshing Materi Electrical \& Electronik Untuk Guru Smk Penerbangan Di Jawa Tengah Dan Sekitarnya. Jubaedah: Jurnal Pengabdian dan Edukasi Sekolah (Indonesian Journal of Community Services and School Education), 1(1), 12-19. https://doi.org/10.46306/jub.v1i1.2

SMK Penerbangan Dirghantara, https://www.smkp-dirghantara.sch.id/profil.html, diakses pada tanggal 16 Juni 2021.

SMK Yappika Legok, https://www.smkyappikalegok.sch.id/profil.php, diakses pada tanggal 16 Juni 2021.

Toni, Wildan, M., Purnomo, S., Wahyudi, J., \& Fatra, O. (2022). Pelatihan Elektronika Dasar Guna Membuka Peluang Kewirausahaan Warga Desa Rancagong Kecamatan Legok Kabupaten Tangerang. $\quad$ Pengmasku, 2(1), 12-20. https://doi.org/https://doi.org/10.54957/pengmasku.v2i1.125

Yohana; Kalbuana, N; Solihin; Yanti, D. R. (2020). The Influence Of Capital Intensity, Firm Size, And Leverage On Tax Avoidance On Companies Registered In Jakarta Islamic Index (Jii) Period 2015-2019. International Journal of Economics, Business and Accounting Research (IJEBAR), 4(03).

Yohana, Gaol, R. M. L., Dewi, G. K., Kalbuana, N., \& Abdusshomad, A. (2021). Pengaruh Free Cash Flow, Profitabilitas, Kualitas Audit, Leverage, Kebijakan Dividen terhadap Likuiditas Pada Perusahaan Terdaftar di Jakarta Islamic Index | Yohana | Jurnal Ilmiah Ekonomi Islam. Jurnal Ilmiah Ekonomi Islam, 7(3). Diambil dari https://jurnal.stieaas.ac.id/index.php/jei/article/view/3601/1660 